\title{
Survival analysis in assessment of influence of the SARS-CoV-2 pandemic on probability and intensity of decline in the value of stock indices
}

Beata Bieszk-Stolorz

University of Szczecin https://orcid.org/0000-0001-8086-9037

Krzysztof Dmytrów ( $\square$ krzysztof.dmytrow@usz.edu.pl)

University of Szczecin https://orcid.org/0000-0001-7657-6063

\section{Research Article}

Keywords: SARS-CoV-2 pandemic, stock indices, survival analysis models, risk assessment

Posted Date: July 15th, 2020

DOI: https://doi.org/10.21203/rs.3.rs-41942/v1

License: (c) (i) This work is licensed under a Creative Commons Attribution 4.0 International License. Read Full License 


\section{Abstract}

The aim of the study is to assess the strength of the world stock exchanges reaction to the SARS-CoV-2 coronavirus pandemic at the turn of 2019-2020. The risk and intensity of the decline in the values of the basic stock indices were analysed. The spreading pandemic within a few months covered all continents and had a significant impact on the socio-economic situation of all countries. The study used methods of duration analysis. The time of the $20 \%$ drop in stock market indices was studied. This is a value that is taken as a sign of crisis. Kaplan-Meier's estimator was used to assess the probability of indices' value decrease. The risk of decline was determined by means of a logit model and the intensity of the decline was determined by means of an empirical hazard estimator and a Cox proportional hazard model. The intensity and risk of decline of stock indices varied from continent to continent. The intensity was highest in the fourth and eighth week after the peak and was highest on European exchanges and then American and Asian exchanges (including Australia). The risk of falling stock indices was highest in America, followed by Europe, Asia and Australia, and lowest in Africa. Half of the analysed indices recorded a 20-percent drop in value after 52 days (median duration). The study is a prelude to further analyses related to the crisis and the normalisation of the situation on world stock exchanges. It allows to learn about the impact of the pandemic on the economic situation and to detect differences between the continents. The methods from the survival analysis are used in the study to assess the impact of the pandemic on the intensity and risk of decline in stock exchange indices.

\section{Introduction}

In December 2019, a new strain of coronavirus (SARS-CoV-2) was spotted in Wuhan, the capital of the Chinese province Hubei. It causes the novel coronavirus disease 2019 (COVID-19). On January 30th, the outbreak was declared the Public Health Emergency of International Concern (PHEIC) by the World Health Organization (WHO). On March 11th, the WHO declared the disease as a global pandemic. As of June 7th, 2020, the total number of infected people around the world is over 7 million and the death toll exceeded the 400 thousand . The SARS-CoV-2 is believed to be the 'the once-in-a-century pathogen' (the previous one was the Spanish influenza in years 1918-1920) (Gates, 2020). Since the declaration of the PHEIC, countries has begun introducing the counter-measures, such as the social-distancing, lockdowns and closing non-essential businesses. This caused the economic slowdown. The full influence of the pandemic on the global economy is not yet known, because it continues to spread and induced by the governments restrictions, although in many countries relaxed, still persist. Also the second wave of pandemic is expected during the autumn 2020 and winter 2020-2021 and it is possible that the restrictions will be reinstated.

The economic impact of the pandemic is visible in many areas, such as decline in the values of stock indexes, fall in crude oil, gold, livestock, grains and other goods prices that were observed during after declaration of the COVID-19 outbreak as the global pandemic. The aim of the study is to assess the strength of the global stock exchange reaction to the SARS-CoV-2 coronavirus pandemic at the turn of 2019-2020. The risk and intensity of the decline in the values of the basic stock indices were analysed. The non-parametric methods of survival analysis (KaplanMeier's estimator was used to assess the probability of indices' value drop) were used in the study. The following research hypothesis was formulated:

$\mathrm{H} 1$ : the risk and intensity of the fall in stock indices varied on a continental level.

\section{Literature Review}

As the COVID-19 pandemic is a relatively new phenomenon (its duration since the official date of the beginning of the outbreak - December 1st, 2019 - is just over six months), the literature referring its economic impact is quite scarce, although many papers started to appear. Although it is obvious that this pandemic will have great impact on the world economy, its strength, directions and range is difficult to assess because its nature is very different, from what we faced in the past (for example the Great Depression in years 1929-1933, the economic crisis 2007-2009 or the Spanish influenza pandemic in years 1918-1920). The main challenges that lie in the present situation, are (Fernandes, 2020):

- it is a global pandemic,

- it is not focused on low-middle income countries,

- interest rates are historically low,

- the world is much more globalised,

- it is generating spill-over effects throughout supply chains,

- supply and demand are simultaneously devastated.

One of the most visual effects of the pandemic was deep decline of prices of many commodities - for example price of barrel of crude oil plunged from over 65 at the beginning of the year to less than 20 USD in mid-April - much lower than in the economic crisis $2007-2009$ (Ji, Zhang and Zhao, 2020). Also prices of other commodities - agricultural products (like grains, edible oils, beverages, fertilisers), metals (copper, aluminium, and even precious metals, except for gold) noted significant drop during spreading of the COVID-19 disease (World Bank, 2020). Also, 
the news-based US index of Economic Policy Uncertainty (EPU) reached the level of over 400 points in April 2020 (Baker et al., 2020 ; Sharif, Aloui and Yarovaya, 2020) - the same was for the global economy. It is worth noting that during the 2007-2009 crisis its value did not exceed 170 points.

The second effect of the COVID-19 pandemic is increase of the number of unemployed persons, thus decrease of the employment rate. The most recent studies indicate that in the USA the employment ratio in February 2020 (just before the outbreak in the USA) was over $61 \%$, while in beginning of April 2020 it was 51\%. The unemployment rate increased from 3.5\% prior to the crisis to almost $11 \%$ in April 2020 (Coibion, Gorodnichenko and Weber, 2020). Sebastian Doerr and Leonardo Gambacorta (2020) assessed the situation on the European labour market in the aspect of employment risk indices. Their main findings were that the highest risk indices were for the regions, where the share of employment in small enterprises is high, as they depend heavily on local demand and are financially constrained. Therefore the highest risk indices are observed in Southern European countries (Italy, Greece, Slovenia, Croatia and in most provinces of France). Baltic states, Visegrad Group countries and Norway were characterised by medium risk indices, while Sweden, Germany, Denmark and the United Kingdom had low risk indices.

However, the first symptom of economic turbulences are visible the most on the changes of stock indices. When the COVID-19 pandemic spreading became apparent, most stock indices noted sharp decline in their values. US stock market reached the circuit breaker mechanism four times in ten days, the main UK's index, FTSE, plunged more than 10\% on March 12th, the day after the state of global pandemic was declared (Zhang, Hu and Ji, 2020). The S\&P 500 index noted a 30\% decline in 16 trading days (Ali, Alam and Rizvi, 2020). B. N. Ashraf (2020) analysed the impact of the number of confirmed COVID-19 cases and deaths on main stock market indices in 64 countries by means of the panel data analysis. His main findings were that reaction of the stock markets on growth of confirmed COVID-19 cases was strong and negative, while the influence of the growth of confirmed deaths on the stock markers was also negative, but the strength of this relationship was much lower than in the former case.

Observation of the stock market during a crisis provides important information on the economic situation of a country or region. Pradhan (2018) has shown that there is a correlation between stock market development and economic growth per capita for the G20 countries using time series from 1980 to 2015 . The author of the study suggests that in order to ensure economic growth, attention should be paid to policies that promote the development of financial institutions and markets, including stock exchanges. Such actions may facilitate further investment and facilitate raising capital to support economic activity. The role of state policy in the process of recovery from the crisis was pointed out by Diemer and Vollmer (2015). They compared Japan with the Nordic countries: Norway, Finland and Sweden. They pointed out that the impact of similar policies on resolving financial crises in these countries in the 1990s was different in each of them. They pointed out that long-lasting political processes, and especially long-term decision making, can make the crisis situation worse.

An interesting way of identifying the financial crisis of 2007-2009 was presented in the work by Olbryś and Majewska (2014). The procedure of determining market conditions of Pagan-Sossounov (2003) was applied to determine the periods of crisis on the basis of an analysis of monthly logarithmic rates of return from the main indices of the Warsaw Stock Exchange - WIG and New York Stock Exchange - S\&P500. According to the definition of bullishops, during a series of quotations there must be a correspondingly large (at least 20\%) increase/decrease in quotations, which means that the amplitude of the bullish phase is greater than or equal to 0.18 , and the amplitude of the bearish phase is less than or equal to -0.22. The identification of a crisis depends on its type. In their article Emin and Aytac (2016) presented 20 different definitions of a currency crisis. They relied, among the others, on research by Reinhart and Rogoff (2009), who assumed that a currency crisis occurs when the value of a currency decreases by at least $15 \%$ during a year compared to the value of the dollar (or other currency accepted in a given country as a reference).

\section{Research Methodology And Statistical Data}

The study used models used in the survival analysis. It is a set of methods aimed at studying the duration of phenomena occurring in various areas of human activity: in social, economic and political life. Originally, these methods were used in demographic research (duration of human life), medical research (recovery time) and technical research (failure-free time of machines and equipment). The methods of survival analysis are increasingly used to study the duration of socio-economic phenomena, including financial issues. The survival analysis methods are rarely used in the capital market analysis. However, in foreign literature there are attempts to use them in this area (Lunde and Timmermann, 2004; Devilleand Riva, 2007; Markovitch and Golder, 2008; Bieszk-Stolorz and Markowicz, 2017, 2018).

The duration of a unit in a given state until a specific event terminating the observation occurs is assumed to be a random variable $T$. A study related to the application of survival models usually involves observation of units belonging to a defined cohort. If the observation period is set, some of the units may not experience the event before its end and the duration is only partially known. Such observations are considered as right censored. A set of all complete and censored observations with survival times no shorter than $t$ is referred to in the literature as a set of risk at time $t$ and denoted by $R(t)$ (Lee, Desu and Gehan, 1975). 
The basic concept is a duration function also called survival function, defined as follows (Kleinbaum and Klein, 2012): (see Formula 1 in the Supplementary Files)

Using formula (1), duration quartiles can be determined. These are the moments of time for which the survival function takes the values $0.75,0.5$ and 0.25 , respectively. The survival function determines the probability that a certain event will not occur at least until time $t$. Depending on the defined event, it is sometimes more convenient to analyse the cumulative distribution function $F(T)$, expressing the probability that the event will not occur at least until time $t$. The most commonly used non-parametric estimator of the survival function is the Kaplan-Meier estimator defined by the formula (Kaplan and Meier 1958): (see Formula 2 in the Supplementary Files)

Despite a relatively large number of non-parametric tests to compare the survival function, there is no consistent group of criteria to decide which of the tests has the greatest power and should be used in the analyses. Studies carried out in Latt's work (1981) indicate that the power of the tests varies depending on the size of the sample being tested, the censorship mechanism and the distribution of the density of the hazard function. In 1972, the Peto brothers proposed a modification of the Wilcoxon test based on Kaplan-Meier's assessment of the survival function for combined samples. This test is used when the hazard ratio between groups is not constant (Stevenson, 2009). Although one of the assumptions of the Peto-Peto test is the equal distribution of censored observations in both groups, the advantage of this test is that it does not lose power in case of different censoring in groups. This test is used when we want to pay more attention to the initial parts of the survival curves.

The second important function in the survival analysis is the hazard function describing the intensity of occurrence of an event at time $t$, provided that it survives to time $t$, defined as follows (Kleinbaum and Klein, 2012): (see Formula 3 in the Supplementary Files)

Do oceny intensywności zajścia zdarzenia w kolejnych jednostkach czasu wykorzystuje się wzór na hazard empiryczny, który ma postać: (see Formula 4 in the Supplementary Files)

The semiparametric Cox hazard model can be used to assess relative hazard, which is defined by means of the formula (Cox, 1972): (see Formula 5 in the Supplementary Files)

This model allows to assess the intensity of the event at moment $t$ in the selected group in relation to the reference group. The hazard ratio is determined by the formula $H R=\exp \left(a_{i}\right)$.

To assess the chance/risk of a relative event, a logit model was used (Kleinbaum and Klein, 2010): (see Formula 6 in the Supplementary Files)

Using the above-described models of survival analysis, 108 major stock exchange indices were examined. Their values were observed from 15 December 2019 to 15 April 2020. A 20\% decrease in the indices was analysed. Due to the pandemic's spread, they were grouped by continents. As only three indices were included in the case of Australia, it was decided to add them to the Asian ones. Thus, four groups of indices have been distinguished: Europe, America, Asia+Australia and Africa. Not all the indices reached the threshold in the analysed period. They are censored observations ( $20 \%$ of them). Table 1 shows in each group the percentage of indices which in the analysed period recorded at least $20 \%$ decrease and those which did not have such a decrease. Additionally, Table 1 presents the maximum and minimum time of decrease in the indices. The first required falls occurred on the $19^{\text {th }}$ day after the peak (Europe), and the last - on the $84^{\text {th }}$ day (also Europe). The highest number of indices did not reach the $20 \%$ drop in Africa (44\%).

Table 1 Structure of indices with respect to the achieved limit values and continents. Source: own elaboration.

\begin{tabular}{|l|c|c|c|c|}
\hline \multicolumn{1}{|c|}{ Groups } & Full observations & Censored observations & Maximal duration (days) & Minimal duration (days) \\
\hline Europe & $84 \%$ & $16 \%$ & 84 & 19 \\
\hline America & $87 \%$ & $13 \%$ & 75 & 20 \\
\hline Asia+Autralia & $82 \%$ & $18 \%$ & 80 & 20 \\
\hline Africa & $56 \%$ & $44 \%$ & 73 & 29 \\
\hline Total & $80 \%$ & $20 \%$ & 84 & 19 \\
\hline
\end{tabular}

\section{Assessment Of The Probability, Intensity And Risk Of Decline In The Value Of Stock Indices}

The study was based on the Dow theory (Rhea, 1932), according to which a $20 \%$ decline in stock market prices is a determinant of the bearishness. Additionally, it is assumed that the phases of the stock exchange cycle (decline, increase, mid-range) should not be shorter than 4 months (Pagan and Sossunov, 2003). For these reasons, the observation period of stock exchange indices lasted from mid-December 2019 to mid-April 2020 (4 months). The initial event was the moment when the index reached its maximum during the observation period, and the final

Page $4 / 9$ 
event was the moment when the index recorded a $20 \%$ decrease in value compared to its maximal one. Random variable $T$ is the time that elapsed between the initial event and the final event. If such a decrease did not occur, the observation is considered censored.

In the first stage, using the Kaplan-Meier estimator, the probability of not achieving a $20 \%$ decrease in the value of all indices together until time $t$ was assessed. The first such decreases were observed starting from day 19 from the moment of reaching the maximum value. Half of the indices recorded a $20 \%$ decrease within 52 days after reaching their maximum value (median duration) (Figure 1, Table 2). Empirical hazard was then determined for all indices altogether. In Figure 2 it can be seen that the highest intensity of the decrease in the indices took place in the fourth and eighth week. These are the two local maxima. It is also visible in the course of Kaplan-Meier estimator in Figure 1 . Between $3^{\text {rd }}$ and $4^{\text {th }}$ week and $7^{\text {th }}$ and $8^{\text {th }}$ week this estimator has significantly higher decreases in its value.

Fig. 1 Kaplan-Meier's estimator - probability of not reaching $20 \%$ decrease in stock indices. Source: own elaboration, STATISTICA.

Fig. 2 Intensity of a $20 \%$ decline in stock market indices - empirical estimator of hazard. Source: own elaboration, STATISTICA.

In the second stage of the study, Kaplan-Meier's estimators were determined for index groups (Figure 3), which were distinguished by their continental belonging. The European stock exchanges recorded the fastest $20 \%$ decrease in the indices, then the American, Asian and Australian ones, and the slowest - African ones. This is indicated both by the mutual position of the duration curves and the quartiles of duration (Table 2). The values of the first quartiles for Europe and America (21 and 22 days) show a faster and similar rate of decline of stock indices. However, in the case of Asia with Australia and Africa the rate was also similar but much slower (50 and 51 days). In addition, the existence of differences between the groups was confirmed by a test for many groups (at a significance level of 0.01 ). A detailed examination with the Peto-Peto test for each pair of groups separately indicated that the null hypothesis about the equality of survival curves should be rejected (at a 0.01 significance level) for pairs: Europe and Asia+Australia and Europe and Africa (Table 3).

Fig. 3 Kaplan-Meier's estimator - probability of not reaching the 20\% decrease in stock market indices by continent. Source: own elaboration, STATISTICA.

Table 2 Quartiles of duration time. Source: own elaboration, STATISTICA.

\begin{tabular}{|l|c|c|c|}
\hline \multicolumn{1}{|c|}{ Groups } & $\begin{array}{c}\text { First quartile } \\
\text { (days) }\end{array}$ & Median (days) & $\begin{array}{c}\text { Third quartile } \\
\text { (days) }\end{array}$ \\
\hline Europe & 21 & 48 & 55 \\
\hline America & 22 & 52 & 61 \\
\hline Asia+Autralia & 50 & 55 & 74 \\
\hline Africa & 51 & 63 & 73 \\
\hline Total & 29 & 52 & 68 \\
\hline
\end{tabular}

Table 3 Results of the Peto-Peto test. Source: own elaboration, STATISTICA.

\begin{tabular}{|l|c|c|}
\hline \multicolumn{1}{|c|}{ Groups } & Test statistics & $p$-value \\
\hline Total & 11.0897 & 0.0113 \\
\hline Europe-America & 1.1351 & 0.2563 \\
\hline Europe-Asia+Australia & 2.6339 & 0.0084 \\
\hline Europe-Africa & 2.6008 & 0.0093 \\
\hline America-Asia+Australia & 1.1806 & 0.2377 \\
\hline America-Africa & 1.4651 & 0.1429 \\
\hline Asia+Australia-Africa & 0.7752 & 0.4382 \\
\hline
\end{tabular}

The third stage of the analysis was to assess relative hazard and the risk of relative decline in indices on each continent. This decline was determined by the geographical location (continent) of the country $\left(x_{i}\right)$. This is a qualitative feature that has been converted into dummy (dichotomous) variables. The number of dummy variables must be one less than the number of categories. Stock exchange indices from African stock exchanges are used as a reference group (coded as 0 ). Earlier analysis showed that this is the continent where the decline in indices was the slowest. There are therefore three variables in the models: $x_{1}$ (Europe), $x_{2}$ (America), $x_{3}$ (Asia + Australia). The limit value for the decrease was assumed to be $20 \%$. In the case of the logit model, the dichotomous variable explained $Y$ takes the value of 1 when there was at least a $20 \%$ decrease in the indices, and the value of 0 in the opposite case. The results of estimation of parameters of both models are presented in Table 4.

Table 4 Results of Cox hazard model and the logit model parameters estimation. Source: own elaboration. 


\begin{tabular}{|c|c|c|c|c|c|}
\hline Variable & Parameter's estimator & Standard error & Wald's statistics & $p$-value & Hazard/odds ratio \\
\hline \multicolumn{7}{|c|}{ Cox hazard model } \\
\hline$x_{1}$ & 0.7563 & 0.3779 & 4.0062 & 0.0453 & 2.13 \\
\hline$x_{2}$ & 0.5181 & 0.4341 & 1.4244 & 0.2327 & 1.68 \\
\hline$x_{3}$ & 0.2946 & 0.3779 & 0.6077 & 0.4357 & 1.34 \\
\hline \multicolumn{7}{|c|}{ Logit model } \\
\hline Intercept & 0.2513 & 0.5040 & 0.2487 & 0.6180 & - \\
\hline$x_{1}$ & 1.4227 & 0.6722 & 4.4789 & 0.0343 & 4.15 \\
\hline$x_{2}$ & 1.6205 & 0.9115 & 3.1604 & 0.0754 & 5.06 \\
\hline$x_{3}$ & 1.2685 & 0.6543 & 3.7590 & 0.0525 & 3.56 \\
\hline
\end{tabular}

For both models, the hazard ratios (HR) and odds ratios (OR) were determined respectively. These are shown on Figure 4 . Their value above 1 indicates an intensity or risk of decline higher than for the reference group (African continent). For both models all the hazard and odds ratios are greater than 1. For Africa alone, as a reference group, they are equal to 1. The decline intensity of the European stock exchange indices was highest and 2.13 times higher than for the African continent, for the American indices 1.68 times and for the Asian indices including the Australian ones 1.34 times higher. The risk of declining stock exchange indices was greatest on American exchanges and about 5 times greater than for African exchanges, for European stock exchanges it was 4.15 times greater, and for Asian and Australian stock exchanges it was 3.56 times greater. This means that the European and American markets reacted with the greatest strength to the pandemic situation.

Fig. 4 The risk and intensity of decline of stock indices. Source: own elaboration.

\section{Conclusion}

The analysis confirmed that the response of global stock markets to the SARS-CoV-2 coronavirus pandemic was varied. The $20 \%$ drop in stock indices characterising the crisis was noticeable in $80 \%$ of the analysed stock exchanges. This shows that all stock exchanges reacted almost simultaneously to the spread of the virus. Analysis of the data indicates that individual stock exchanges differed with respect to the moment when the maximum value of indices was recorded, but the biggest drops took place in March 2020. This took place after the WHO declared a state of pandemic (11 March 2020). That is why there are differences in risk and intensity of falls observed in different countries and on different continents. The greatest risk of decline was on American stock exchanges. This is due to the fact that as much as $87 \%$ of indices lost $20 \%$ of their value. On the other hand, European exchanges were characterized by the highest intensity of falls, which results from the fact that there was the shortest time of fall from the maximum value (median duration equal to 48 days) with a high percentage of indices that reached the required limit. This can be explained by the fact that a large increase in the number of cases in Europe occurred earlier than on the American continent. During this time, the lowest or no index decreases were observed in African countries. On the Asian continent the situation was ambiguous. In China and South Korea large increases in the coronavirus cases were observed at the beginning of the pandemic, while in Iran the increase occurred at a similar time as in European countries. In other Asian countries, e.g. India, the pandemic situation started to develop later. This confirms the research hypothesis. The article is an introduction to further research. Interesting is the chance and intensity of the increase in the value of indices to pre-crisis levels and the impact of the second wave of the disease on the stock market, expected in autumn 2020.

\section{Declarations}

\section{Conflict of interest}

The authors declare that they have no conflicts of interest.

\section{References}

Ali, M., Alam, N., \& Rizvi, S. A. R. (2020). Coronavirus (COVID-19) - An epidemic or pandemic for financial markets. Journal of Behavioral and Experimental Finance, https://doi.org/10.1016/j.jbef.2020.100341.

Ashraf, B. N. (2020). Stock markets' reaction to COVID-19: Cases or fatalities? Research in International Business and Finance, https://doi.org/10.1016/j.ribaf.2020.101249.

Baker, S. R., Bloom, N., Davis, S. J., \& Terry, S. J. (2020). COVID-Induced Economic Uncertainty. NBER Working Paper No. 26983, https://doi.org/10.3386/w26983. 
Bieszk-Stolorz, B., \& Markowicz, I. (2017). Methods of Event History Analysis in the Assessment of Crisis Impact on Sectors Related with the Real Estate Market in Poland. Folia Oeconomica Stetinensia, https://doi.org/10.1515/foli-2017-0005.

Bieszk-Stolorz, B., \& Markowicz, I. (2018). Application of models of survival analysis in the assessment of the situation of macrosectors of listed companies. Optimum. Economic Studies, https://doi.org/10.15290/oes.2018.01.91.01.

Coibion, O., Gorodnichenko, Y., \& Weber, M. (2020). Labor Markets During the Covid-19 Crisis: A Preliminary View, NBER Working Paper No. 27017, https://doi.org/10.3386/w27017.

Cox, D. R., (1972). Regression Models and Life-Tables. Journal of the Royal Statistical Society, Series B (Methodological), 34(2), $187-220$.

Deville, L., \& Riva F. (2007). Liquidity and Arbitrage in Options Markets: A Survival Analysis Approach, Review of Finance, https://doi.org/10.1093/rof/rfm021.

Diemer, M., \& Vollmer, U. (2015). What makes banking crisis resolution difficult? Lessons from Japan and the Nordic Countries. Eurasian Economic Review, https://doi.org/10.1007/s40822-015-0026-5.

Doerr, S., \& Gambacorta, L. (2020). Covid-19 and regional employment in Europe. BIS Bulletin No 16.

Emin, D., \& Aytac, A. (2016). The challenge of predicting currency crises: how do definition and probability threshold choice make a difference? Eurasian Economic Review, https://doi.org/10.1007/s40822-016-0051-z.

Fernandes, N. (2020). Economic effects of coronavirus outbreak (COVID-19) on the world economy, https://doi.org/10.2139/ssrn.3557504.

Gates, B. (2020). Responding to Covid-19-A once-in-a-century pandemic? New England Journal of Medicine, https://doi.org/10.1056/NEJMp2003762.

Ji, Q., Zhang, D., \& Zhao, Y. (2020). Searching for safe-haven assets during the COVID-19 pandemic. International Review of Financial Analysis, https://doi.org/10.1016/j.irfa.2020.101526.

Kaplan, E. L., \& Meier, P. (1958). Nonparametric estimation from incomplete observations. Journal of the American Statistical Association, https://doi.org/10.2307/2281868.

Kleinbaum, D. G., \& Klein, M. (2010). Logistic Regression. A Self-Learning Text. Third Edition. New York: Springer-Verlag, https://doi.org/10.1007/978-1-4419-1742-3.

Kleinbaum, D. G., \& Klein, M. (2012). Survival Analysis. A Self-Learning Text. Third Edition. New York: Springer-Verlag, https://doi.org/10.1007/978-1-4419-6646-9.

Latta, R. B. (1981). A Monte Carlo study of some two-sample rank tests with censored data. Journal of the American Statistical Association, https://doi.org/10.2307/2287536.

Lee, E.T., Desu, M. M., \& Gehan, E. A., (1975). A Monte Carlo Study of the Power of Some Two-sample Tests. Biometrika, https://doi.org/10.2307/2287536.

Lunde, A., \& Timmermann, A. (2004). Duration Dependence in Stock Prices: An Analysis of Bull and Bear Markets. Journal of Business \& Economic Statistics, https://doi.org/10.1198/073500104000000136.

Markovitch, D. G., \& Golder, P. N. (2008). Findings - Using Stock Prices to Predict Market Events: Evidence on Sales Takeoff and Long-Term Firm Survival. Marketing Science, https://doi.org/10.1287/mksc.1070.0325.

Olbryś, J., \& Majewska, E. (2015). Bear Market Periods During the 2007-2009 Financial Crisis: Direct Evidence From the Visegrad Countries. Acta Oeconomica, https://doi.org/10.1556/032.65.2015.4.3.

Pagan, A. R., \& Sossounov, K. A. (2003). A Simple Framework for Analysing Bull and Bear Markets. Journal of Applied Econometrics, https://doi.org/10.1002/jae.664.

Peto, R., \& Peto, J. (1972). Asymptotically efficient rank invariant test procedures. Journal of the Royal Statistical Society, https://doi.org/10.2307/2344317.

Pradhan, R. P. (2018). Development of stock market and economic growth: the G-20 evidence. Eurasian Economic Review, https://doi.org/10.1007/s40822-018-0094-4. 
Reinhart, C., \& Rogoff, K. (2009). This time is different: a panoramic view of eight centuries of financial crises. NBER Working Paper No. 13882, https://doi.org/10.3386/w13882.

Rhea R. (1932). The Dow Theory. Barron's: New York.

Sharif, A., Aloui, C., \& Yarovaya L. (2020). COVID-19 pandemic, oil prices, stock market, geopolitical risk and policy uncertainty nexus in the US economy: Fresh evidence from the wavelet-based approach. International Review of Financial Analysis, https://doi.org/10.1016/j.irfa.2020.101496.

Stevenson, M., (2009). An Introduction to Survival Analysis, EpiCentre, IVABS. Massey Massey University. http://www.massey.ac.nz/massey/fms/Colleges/College\%20of\%20Sciences/Epicenter/docs/ASVCS/Stevenson_survival_analysis_195_721.pdf. Accessed 05 June 2020.

World Bank. (2020). A World Bank Report. April 2020. Commodity Markets Outlook. Implications of COVID-19 for Commodities. Publishing and Knowledge Division, World Bank: Washington. https://openknowledge.worldbank.org/bitstream/handle/10986/33624/CMO-April-020.pdf. Accessed 05 June 2020.

Zhang, D., Hu, M., \& Ji, Q. (2020). Financial markets under the global pandemic of COVID-19. Finance Research Letters, https://doi.org/10.1016/j.frl.2020.101528.

\section{Figures}

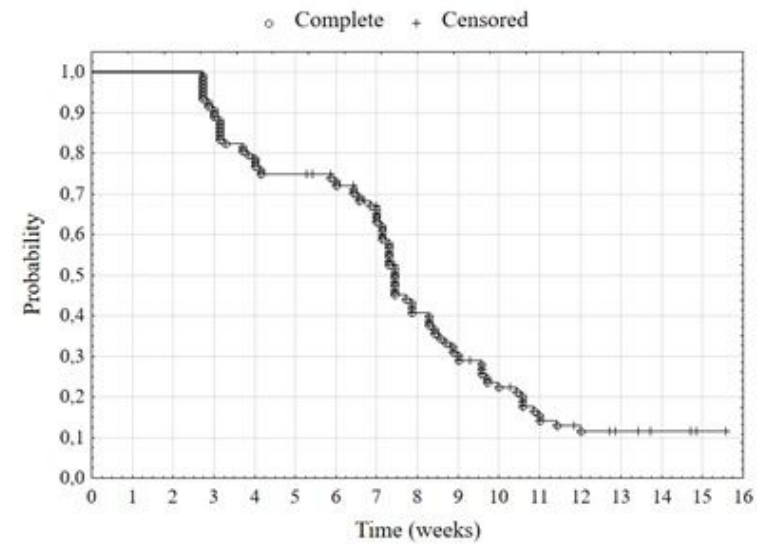

\section{Figure 1}

Kaplan-Meier's estimator - probability of not reaching $20 \%$ decrease in stock indices. Source: own elaboration, STATISTICA.

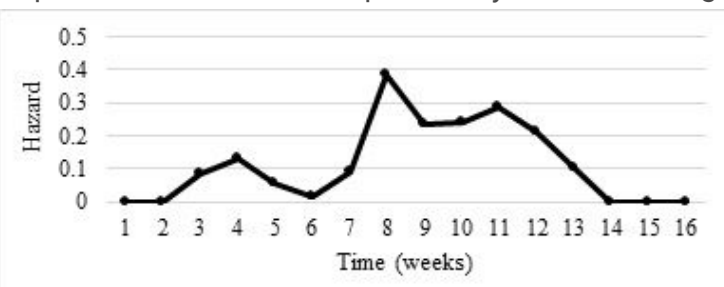

Figure 2

Intensity of a $20 \%$ decline in stock market indices - empirical estimator of hazard. Source: own elaboration, STATISTICA. 


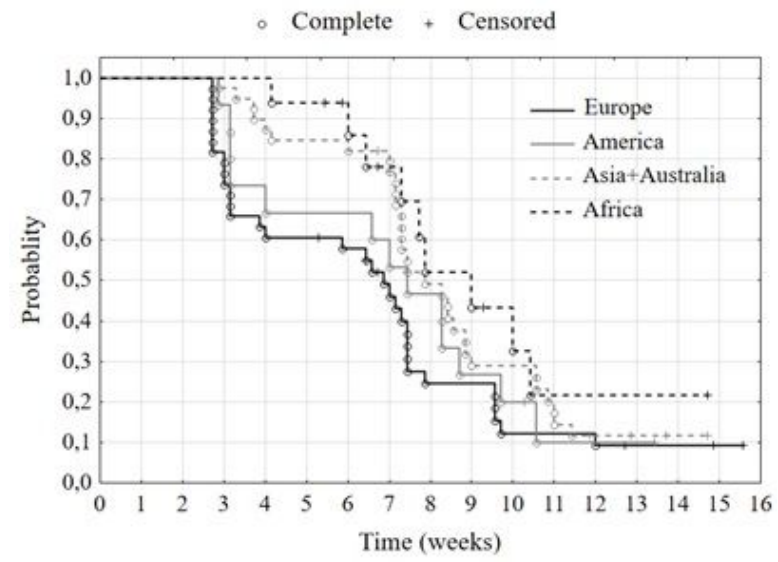

Figure 3

Kaplan-Meier's estimator - probability of not reaching the $20 \%$ decrease in stock market indices by continent. Source: own elaboration, STATISTICA.

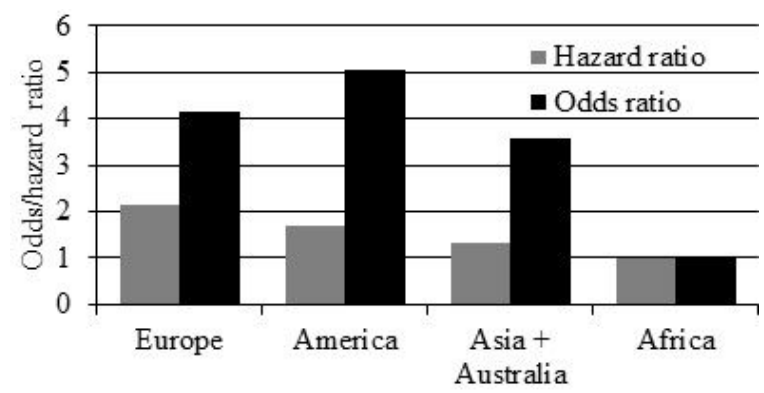

Figure 4

The risk and intensity of decline of stock indices. Source: own elaboration.

\section{Supplementary Files}

This is a list of supplementary files associated with this preprint. Click to download.

- Formulas.pdf 